\title{
Studi Kualitatif Pemahaman Perawat Intensive Care Unit tentang Pengkajian Nyeri Behaviour Pain Scale
}

\author{
Fatimah Khoirini $^{1^{*}}$, Rahma Annisa ${ }^{2}$ \\ ${ }^{1,2}$ Prodi Keperawatan Curup, Poltekkes Kemenkes Bengkulu, Curup, Indonesia \\ ${ }^{2}$ Jurusan Keperawatan, Poltekkes Kemenkes Bengkulu, Bengkulu, Indonesia \\ *fatimahkhoirini80@gmail.com
}

\begin{abstract}
Assessment is the initial nursing process. In the nursing assessment obtained information about patient data used as a baseline and determine the next stage. Patients in intensive rooms with ventilators often received nursing actions that cause pain. Pain assessment in patients using ventilators must use special assessment techniques. Patients with ventilators require standardized assessment methods because they cannot communicate the pain they feel verbally. Payen in 2001 developed the Behavioral Pain Scale (BPS). Critical patients who are fitted with ventilators need a systematic and consistent assessment of pain. Understanding is the ability to explain correctly and in detail about something. Before performing an action properly one needs to understand the action. This study aimed to determine the experience and understanding of ICU nurses about pain assessment using BPS at M Yunus Bengkulu General Hospital. This study used the qualitative study that focus on disclosing nurses' understanding of pain assessment using BPS. Themes that emerged in this study were 1. use BPS, 2. Three items in the BPS assessment, 3. Indicators assessing pain, 4. Maximum minimum scoring, 5. Range of pain values. Nurse's understanding about BPS was very necessary.
\end{abstract}

Keyword: behavioral pain scale, understanding, nurse, qualitative

\begin{abstract}
Abstrak
Pengkajian merupakan tahap awal proses keperawatan. Pada pengkajian keperawatan didapatkan informasi tentang data pasien yang digunakan sebagai data dasar dan menentukan tahap selanjutnya. Pasien di ruang intensif yang terpasang ventilator sering mendapatkan tindakan keperawatan yang menimbulkan rasa nyeri. Pengkajian nyeri pada pasien yang memakai ventilator harus menggunakan tehnik pengkajian khusus, pasien yang terpasang ventilator memerlukan cara penilaian terstandar karena tidak dapat mengkomunikasikan rasa nyeri yang dirasakannya secara verbal. Payen tahun 2001 mengembangkan Behavioral Pain Scale (BPS) Pasien kritis yang terpasang ventilator membutuhkan penilaian nyeri yang sistematis dan konsisten. Memahami adalah kemampuan dapat menjelaskan secara benar dan terperinci tentang sesuatu. Sebelum melakukan tindakan dengan baik seseorang perlu memahami tindakan tersebut. Penelitian ini bertujuan mengetahui pengalaman dan pemahaman perawat ICU tentang pengkajian nyeri menggunakan BPS di RSUD M Yunus Bengkulu. Penelitian ini menggunakan studi kualitatif yang berfokus pada pengungkapan pemahaman perawat tentang pengkajian nyeri menggunakan BPS. Tema yang muncul dalam penelitian ini adalah 1. Guna BPS, 2. Tiga item dalam pengkajian BPS, 3. Indikator menilai nyeri, 4. Skoring minimal maksimal, 5. Rentang nilai nyeri. Pemahaman perawat tentang BPS sangat diperlukan.
\end{abstract}

Kata kunci: behavioral pain scale, pemahaman, perawat, kualitatif

Jurnal Keperawatan Raflesia, Volume 1 Nomor 2, November 2019

ISSN: (p) 2656-6222 (e) 2657-1595, DOI 10.33088/jkr.vli2.411

Available online: https://jurnal.poltekkes-kemenkes-bengkulu.ac.id/index.php/jkr 


\section{PENDAHULUAN}

Pengkajian merupakan tahap awal pada proses keperawatan (Hidayat, 2002). Pada pengkajian keperawatan didapatkan informasi tentang data pasien yang digunakan sebagai data dasar dan untuk menentukan tahap selanjutnya.

Pengumpulan data dapat dilakukan dengan observasi, pemeriksaan fisik, diagnostik dan wawancara (Asmadi, 2008). Salah satu data keperawatan yang didapat dari hasil wawancara adalah pengkajian nyeri. Pengkajian nyeri perlu dilakukan dengan sistematik karena bagian dari proses keperawatan. Pengkajian nyeri dilakukan agar perawat dapat mengevaluasi nyeri pasien yang bersifat individu (Sriwahyuningsih, 2016).

Tehnik wawancara yang digunakan untuk mengetahui karakteristik nyeri berupa Provokes/palliates, Quality, Radiates, Severity, Time (PQRST) (Muttaqin, 2008). Pengkajian nyeri pada pasien yang memakai ventilator harus menggunakan tehnik pengkajian nyeri khusus, Pasien yang terpasang ventilator memerlukan cara penilaian terstandar karena pasien tidak dapat mengkomunikasikan rasa nyeri yang dirasakannya secara verbal (Coyer dkk, 2007). Pasien kritis yang terpasang ventilator membutuhkan penilaian nyeri yang sistematis dan konsisten (Rahu, 2010).

Instrumen pengkajian nyeri khusus untuk pasien kritis ada beberapa macam yaitu, NVPS atau Nonverbal Adult Pain
Assessment Scale (Odhner, 2003), P.A.I.N atau Pain Assessment and Intervention Notation Algorithm (Puntillo, 2004), Comfort Scale, BPS atau Behavioural pain scale (Payen, 2009) dan CPOT atau Critical-Care Pain Observasion Tool (Gelinas, 2009).

Pasien di ruang intensif yang terpasang ventilator sering mendapatkan tindakan keperawatan yang efeknya menimbulkan rasa nyeri. Pasien yang terpasang ventilator mempunyai pengalaman nyeri yang berbeda-beda. Tujuh puluh satu persen dari lima juta orang yang dirawat di ruang intensif menyatakan selama menjalani perawatan, ia merasakan nyeri (Stites, 2013). Pasien dewasa yang terpasang ventilator mengeluh nyeri karena efek pengobatan, tindakan perawatan, dan patofisiologi penyakit (Cade, 2008). Menurut Sutari (2014) prosedur keperawatan yang sering mengakibatkan nyeri yaitu, pemasangan atau pelepasan kateter, suction trakea, perubahan posisi pasien serta penggantian balutan luka.

Hasil penelitian Aissaoui et al (2005) Pengamatan pada 30 pasien ICU menggunakan Behavioural pain scale (BPS), nilai reliabilitas BPS dengan cronbach alfa 0.72, dari 3 observer didapat nilai interrater reliability 0.95 , dan nilai validitas yaitu $\mathrm{P}<0.001$. Berdasarkan penelitian Sriwahyuningsih (2016) didapat bahwa instrument pengkajian nyeri pada pasien dewasa kritis yang tidak mampu menyatakan nyeri yang dirasakannya secara verbal menggunakan BPS dan CPOT. BPS dan $\mathrm{CPO}$ mempunyai nilai reliabilitas dan 
validitas lebih tinggi dari ketiga instrumen lainnya.

Payen et al (2001) mengembangkan instrument pengkajian nyeri pada pasien kritis menggunakan BPS. Instrumen pengkajian BPS terdiri dari tiga komponen, yaitu dilihat dari ekspresi wajah, gerakan ekstremitas atas dan komplain saat pemakaian ventilator. Masing- masing komponen mempunyai skor antara 1-4, hasil penilaian dikategorikan dengan tidak nyeri sampai sangat nyeri (skor 3-12). BPS mempunyai kelebihan dapat digunakan pada pasien kritis di ICU yang menggunakan intubasi dan tidak menggunakan intubasi (Sriwahyuningsih, 2016).

Rumah sakit M.Yunus adalah salah satu rumah sakit di propinsi Bengkulu yang menyediakan pelayanan Unit Perawatan Intensif dengan jumlah tempat tidur 9 buah diruang ICU dan 14 buah di ruang ICCU dengan BOR 50,55. Pada survey peneliti pada bulan Desember 2016 di dapat 2 pasien yang menggunakan ventilator dan untuk pengkajian nyeri belum menggunakan teknik khusus (RSUD, 2016).

Hasil pengkajian harus benar dan akurat sehingga menunjang untuk pelaksanaan asuhan keperawatan selanjutnya. Pengkajian sangat dibutuhkan untuk memastikan diagnosis, kesalahan dalam mengkaji nyeri yang spesifik pada pasien yang menggunakan ventilator dapat meningkatkan risiko kesalahan dalam pemberian asuhan keperawatan yang tepat, kesalahan dalam mendiagnosis dan kesalahan dalam menentukan altenatif pengobatan yang tepat (Asmadi, 2008).
Sebelum dapat melakukan suatu tindakan dengan baik seseorang perlu tahu tentang sesuatu kemudian memahami tentang tindakan tersebut. (Notoatmodjo, 2005). Jika diaplikasikan pada kegiatan kerja perawat di ruang ICU maka perawat dapat melaksanakan pengkajian nyeri menggunakan Behavioural Pain Scale dengan baik jika ia telah memahami tentang Behavioural Pain Scale. Memahami prosedur tindakan sebelum mengerjakan sesuatu agar tujuan dari pekerjaan yang kita laksanakan sesuai dengan ekpekstasi yang kita harapkan. hasilnya maksimal, memuaskan dan tersusun rapi sesuai langkah pengerjaannya. Peneliti menggunakan metode kualitatif dalam penelitian ini untuk menggali pemahaman perawat tentang BPS secara alamiah, apa adanya sehingga didapat data penelitian secara utuh.

Penelitian ini bertujuan mengetahui pemahaman perawat ICU tentang pengkajian nyeri menggunakan BPS di RSUD M Yunus Bengkulu. Berdasarkan latar belakang diatas peneliti tertarik untuk meneliti tentang pemahaman perawat tentang pengkajian nyeri menggunakan Behaviour Pain Scale (BPS) di Ruang Intensif Care Unit di RSUD M Yunus Bengkulu.

\section{METODE}

Penelitian tentang pemahaman perawat tentang pengkajian nyeri dengan BPS ini menggunakan studi kualitatif yang berfokus pada pengungkapan pemahaman perawat tentang pengkajian nyeri menggunakan Behaviour Pain Scale (BPS) di Ruang Intensif Care Unit RSUD dr. M. Yunus Bengkulu. Desain fenomenologi 
dapat memberikan gambaran, interpretasi, refleksi, dan menyampaikan pengalaman responden yang sedang diteliti. Desain ini mencari lebih dalam pemahaman tentang ide, perilaku dan tindakan serta gagasan individu terhadap suatu hal (Afiyanti \& Rachmawati, 2014).

Langkah kerja yang harus dilakukan oleh peneliti dalam desain ini menurut Polit dan Beck (2012) adalah: bracketing, intuisi, analisis dan deskripsi serta interpretasi. Bracketing adalah proses yang dilakukan peneliti dalam menyimpan semua asumsi, pengetahuan dan keyakinan yang dimilikinya tentang hal yang diteliti sehingga informasi yang diperoleh berasal dari partisipan tanpa dipengaruhi oleh pengetahuan, keyakinan dan asumsi peneliti. Intuisi yaitu keadaan peneliti mengenali dan memahami hal yang sedang diteliti. Pada proses ini, peneliti tidak diperbolehkan memberikan opini, evaluasi dan kecaman, agar peneliti tidak kehilangan konsentrasi terhadap informasi yang sedang digali. Analisis yaitu proses menganalisa informasi atau data yang telah dikumpulkan. Analisis dapat dilakukan dengan langkah membaca data yang telah terkumpul, memilih kata kunci, mengidentifikasi arti kata kunci, mengelompokkan beberapa kategori menjadi tema, menulis pola hubungan antartema dalam narasi sementara, melakukan validasi narasi kepada partisipan, membuat deskripsikan hasil ahir validasi dan menuliskan dalam narasi. Hasil penelitian dan pembahasan dari fenomena yang diteliti dideskripsikan atau diinterpretasikan oleh peneliti untuk menyampaikan hasil ahir penelitian kepada pembaca dalam bentuk gambaran tertulis fenomena yang diteliti.

\section{Subjek Penelitian}

Partisipan penelitian ini adalah perawat yang bekerja di Ruang Intensif Care Unit RSUD dr. M. Yunus Bengkulu dan menandatangani lembar persetujuan sebagai partisipan sebagai tanda bersedia terlibat dalam penelitian. Menurut Afiyanti \& Rachmawati (2014), pemilihan partisipan dalam penelitian kualitatif dilakukan dengan metode purposive sampling, dimana pemilihan partisipan harus berdasarkan kriteria, keadaan atau unit waktu yang ditetapkan. Jenis sampel yang digunakan adalah sampel homogeny, dimana yang diteliti adalah perawat yang bekerja di ICU RSUD M. Yunus Bengkulu. Partisipan dalam penelitian ini sebanyak 10 perawat.

\section{Prosedur Penelitian}

Proses pengumpulan data diawali dengan persiapan mencari informan dengan cara mendatangi ruang ICU RSUD M.Yunus, meminta izin kepada kepala ruangan untuk melakukan penelitian dan berkenalan dengan perawat, menyampaikan maksud dan tujuan kedatangan dan tujuan penelitian serta menjelaskan prosedur penelitian kemudian menawarkan kepada perawat apakah bersedia menjadi informan. Jika bersedia, dapat mengisi lembar persetujuan menjadi informan. Dilanjutkan dengan kontrak waktu dengan partisipan, melakukan wawancara mendalam serta melakukan terminasi.

\section{Instrumen Pengumpulan Data}

Pada penelitian kualitatif, intrumen pengumpulan data adalah human instrument atau peneliti sendiri. Sebagai instrument penelitian, peneliti berpedoman pada panduan wawancara. Fungsi pedoman wawancara ini adalah untuk mengarahkan peneliti untuk menggali lebih mendalam tentang fenomena yang sedang diteliti. 
Peneliti perlu menyiapkan alat bantu lain yang dapat digunakan selama proses wawancara seperti alat perekam yang bertujuan untuk memperlancar proses wawancara.

\section{Analisis Data}

Proses analisis data pada penelitian diawali dengan peneliti menulis transkrip berasarkan hasil wawancara yang telah direkam, membaca transkrip tersebut untuk memperoleh makna secara keseluruhan dari hasil wawancara, mengidentifikasi kata kunci dari pernyataan-pernyataan spesifik yang dikatakan oleh partisipan, membuat kategori dari kata-kata kunci yang telah dipilih dan kategori-kateori yang telah terbentuk akan disusun membentuk subtema yang kemudian akan digolongkan dalam bentuk tema-tema, selanjutnya peneliti melakukan pengecekan kembali kepada partisipan mengenai data-data yang telah dikumpulkan.

\section{Keabsahan Data}

Untuk menjaga keabsahan data, ada beberapa hal yang harus dilakukan yaitu: Crediblility, Dependability, Confirmability, Transferability. Crediblility / Kredibilitas data dilakukan dengan melakukan wawancara langsung, membuat transkrip secara verbatim, melakukan analisis dan melakukan pengecekan kembali kepada partisipan. Dependability adalah telaah data dan dokumen yang diperoleh harus dilakukan melalui inquiry audit yang dilakukan oleh tim reviewer dengan mereview aktivitas peneliti selama proses penelitian. Confirmability adalah menyerahkan transkrip dalam bentuk verbatim kepada tim reviewer untuk diaudit sehingga kebenaran hasil data dapat diketahui. Transferability adalah peneliti melakukan pembahasan hasil penelitian terhadap hasil penelitian dan literature terkait. Hasil penelitian juga diharapkan dapat ditrasnfer ke subjek lain yang memiliki tipologi yang sama

\section{HASIL}

\section{Pemahaman perawat tentang Behaviour Pain Scale (BPS)}

Hasil wawancara yang telah dilakukan dikategorikan menjadi 5 tema yang menunjukkan pemahaman perawat tentang BPS. Wawancara tentang pemahaman perawat didapat hasil sebagai berikut :

\section{Guna BPS}

Perawat ICU memahami BPS digunakan untuk menilai skala nyeri pasien dengan penurunan kesadaran dan menggunakan ventilator sesuai dengan pernyataan informan berikut :

"BPS itu sebuah cara untuk kita menilai skala nyeri pasien dengan penurunan kesadaran dengan pasien ventilator dimana penilaian tersebut berdasarkan 3 hal yang kita lihat seperti ekspresi prilakunya, ekspresi wajah, kemudian pergerakan ekstremitasnya dan kita lihat kompensasi pasien-pasien itu terhadap penggunaan ventilatornya”.(Tn Y,33 tahun, R1)

"Itu untuk mengukur skala nyeri pasien dengan penurunan kesadaran dan menggunakan ventilator dimana penilaian tersebut berdasarkan 3 ekspresi, yaitu prilaku, ekspresi wajah pergerakan ekstremitas atas dan kompensasi terhadap ventilator"'(Tn WS,35 tahun, R9) 


\section{Tiga item dalam pengkajian BPS}

Perawat ICU memahami ada 3 item dalam pengkajian BPS seperti pernyataan informan berikut :

"Ada 3, satu ekspresi wajah, dua pergerakan ekstremitas atas, tiga kompensasi terhadap ventilator".(Ny YS, 30 tahun, R7)

"Iya.. pasien dengan ventilator. Penilaian ini biasanya kita menggunakan tiga item, yang pertama dengan ekspresi wajah, kedua dengan pergerakan ekstremitas atas, ketiga dengan kompensasi tubuh terhadap ventilator"(Tn M, 37 tahun, $R 3$ )

\section{Indikator menilai nyeri}

Perawat ICU memahami indikator menilai nyeri menggunakan BPS seperti pernyataan informan berikut :

“...... ekspresi wajahnya kalau dia santai itu 1, ekspresi wajah sedikit mengkerut ....... biasanya 2, kemudian ekspresi wajahnya mengerut penuh ... sampai memejamkan mata biasanya .. 3, ....... pasien sampai meringis ...... nilai 4. ... kedua ... pergerakan ekstremitas atas.... tidak ada pergerakan ekstremitas atas dia terlihat santai itu kita beri nilai 1, kemudian kalau misalnya ekstemitas atasnya sedikit ... membengkok itu kita kasih nilai 2, kemudian eksremitas atasnya membengkok sedikit itu dengan fleksi pada jarinya itu 3, kemudian pada ekstremitas atasnya retraksi permanen itu 4. ... kompensasi terhadap ventilator, biasanya mengikuti ventilator itu ee.. biasanya 1, ada juga pasien dengan ventilator itu kan dia pasien sendiri yang mengatakan enak menggunakan ventilator itu nilainya 1, kemudian kompensasi pada pasien ventilator ini sering batuk dengan pergerakan biasanya nilai nyerinya 2, jika pasien berontak atau melawan ventilator atau fighting itu biasanya 3, kemudian jika pasien tidak mampu mengontrol ventilator itu sendiri biasanya 4 itu nilainya.(Tn $Y, 33$ tahun, Rl)

\section{Skoring minimal dan maksimal}

Perawat ICU memahami pemberian nilai dalam BPS yaitu nilai minimal 3 dan nilai maksimal 12 seperti pernyataan informan berikut :

"Kalau nilai maksimal pengkajian BPS maksimalnya 12, kalau minimal 3"'(Tn WS, 35 tahun, R9)

"Karena ada 3 katagori maksimalnya 12, jika nilainya 1 semua maka nilai minimalnya 3")(Tn MD,27 tahun, R10)

\section{Rentang nilai nyeri}

Perawat ICU memahami rentang nilai dalam katagori nyeri menurut BPS yaitu nyeri ringan dengan nilai 3 - 5, nyeri sedang dengan nilai 6 - 8 dan nyeri berat dengan nilai 9 - 12 seperti pernyataan informan berikut :

"Menurut BPS rentang nyeri ini dapat kita golongin 3 yaitu pada nyeri ringan itu dapat kita nilai 3-5, kemudian kalau nyeri sedang 6-8, jika nyeri berat itu nilainya 9-12”. (Ny $R, 36$ tahun, $R 4$ ) 
"Rentang nilai pada nyeri ringan 35,kalau nyeri sedang 6-8,kalau nyeri berat 9-12"(Tn WS,35 tahun, R9)

\section{PEMBAHASAN}

Pada penelitian ini perawat ICU menyatakan untuk mengkaji nyeri pasien yang mengalami penurunan kesadaran dan yang mengunakan ventilator menggunakan Behavioural pain scale ini sesuai dengan Coyer et all (2007) pengkajian nyeri pada pasien yang dirawat di ruang intensif care yang memakai ventilator harus menggunakan tehnik penilaian terstandar karena pasien tidak dapat mengkomunikasikan rasa nyeri yang dirasakannya secara verbal. Hasil penelitian Aissaoui et al (2005) Pengamatan pada 30 pasien ICU menggunakan Behavioural pain scale (BPS), BPS memiliki nilai reliabilitas dengan cronbach alfa 0.72 , nilai interrater reliability antara 3 observer sebesar 0.95 , dan nilai validitas sebesar $\mathrm{P}<0.001$. BPS dan CPOT merupakan instrumen pengkajian nyeri yang valid dan reliabel untuk menilai nyeri pada pasien kritis dewasa yang tidak mampu melaporkan nyeri secara verbal. Nilai reliabilitas dan validitas pada instrumen BPS dan CPOT lebih tinggi dari ketiga instrumen lainnya Sriwahyuningsih (2016).

Memahami merupakan satu tingkat lebih tinggi dari tahu dalam tingkatan pengetahuan. Jika tahu hanya bersifat hapalan, maka memahami memerlukan kemampuan menangkap makna suatu konsep (Sudjana, 2013). Sebelum dapat melakukan suatu tindakan dengan baik seseorang perlu tahu kemudian memahami tentang tindakan tersebut. (Notoatmodjo, 2005). Jika diaplikasikan pada kegiatan kerja perawat di ruang ICU maka perawat dapat melaksanakan pengkajian nyeri menggunakan Behavioural Pain Scale dengan baik jika ia telah memahami tentang Behavioural Pain Scale.

Pada penelitian ini informan telah dapat menjelaskan tentang kegunaan Behavioural Pain Scale sesuai dengan Payen et al tahun 2001 mengembangkan instrument pengkajian nyeri pada pasien kritis menggunakan BPS. BPS mempunyai kelebihan dapat digunakan pada pasien kritis di ICU yang menggunakan intubasi dan tidak menggunakan intubasi (Sriwahyuningsih, 2016).

Pemahaman perawatan tentang cara memberi skor dan kategori nyeri, informan dapat menjelaskan tentang cara memberi skor serta katagori nyeri menggunakan Behavioral Pain Scale sesuai dengan Payen et al (2001) tentang Instrumen pengkajian BPS terdiri dari tiga komponen, yaitu dilihat dari ekspresi wajah, gerakan ekstremitas atas dan komplain saat pemakaian ventilator. Masing- masing komponen mempunyai skor antara 1-4, hasil penilaian dikategorikan dengan tidak nyeri sampai sangat nyeri (skor 3-12).

Perawat dapat menjelaskan tentang Behavioral Pain Scale mulai dari kegunaan, jumlah item penilaian, indicator menilai nyeri, nilai minimal dan nilai maksimal serta rentang nilai nyeri ini sesuai dengan Notoatmodjo (2005) bahwa memahami adalah kemampuan dapat menjelaskan secara benar dan terperinci tentang suatu objek. 


\section{KESIMPULAN}

Hasil penelitian pemahaman perawat tentang pengkajian nyeri menggunakan BPS dapat menjadi salah satu contoh bagi pengambil keputusan di Rumah Sakit untuk mengadakan evaluasi rutin bagi perawat tentang semua tindakan di ruang ICU. Berdasarkan hasil penelitian ini hendaknya petugas yang belum memahami BPS dapat mempelajari BPS lebih lanjut, serta petugas lain yang sudah mengetahui suatu metode baru dapat membagi ilmunya kepada rekan yang belum mengetahui metode baru tersebut.

\section{DAFTAR PUSTAKA}

Aissaoui, Y., Zeggwagh, A., \& Zekraoui, A. (2005) . Validation of a behavioral pain scale in critically ill, sedated and mechanically ventilated patients. Anesthiology Journal, 101, 1470-6.

Afiyanti, Y., \& Rachmawati, N. I. (2014). Metodologi penelitian kualitatif dalam riset keperawatan. (Edisi 1). Jakarta: Rajawali Pers.

Asmadi. (2008). Konsep dasar keperawatan. Jakarta: EGC.

Cade, C. H. (2008). Clinical tools for the assessment of pain in sedated critically ill adults. Nurs Critical Care, 13(6), 288$97 . \quad$ doi:10.1111/j.1478 5153.2008.00294.x.

Coyer ,FM., Wheeler, MK., Wetzig, SM., \& Couchman, BA. (2007). Nursing care of the mechanically ventilated patient: What does the evidence say. Part two. Intensive Crit Care Nurs, 23(2), 71-80.

Gelinas, C., Harel, F., Fillion, L., Puntillo K. A., \& Johnston, C. C. (2009) Sensitivity and specificity of the critical-care pain observation tool for the detection of pain in intubated adults after cardiac surgery. Journal Pain Symptom Management, 37(1), 58-67.

Hidayat, A. A. (2002). Pengantar dokumentasi proses keperawatan. Jakarta: EGC.

Muttaqin, A. (2008). Buku ajar asuhan keperawatan dengan gangguan sistem syaraf. Jakarta: Salemba Medika.

Notoatmodjo, S. (2005). Pendidikan dan perilaku kesehatan. Jakarta: PT Rineka Cipta.

Odhner, M., Wegman, D., \& Freeland, N. (2003). Assessing pain control in nonverbal critically ill adults. Journal of Research in Medical Science, 22, 2607.

Payen, J. F. (2009). assessing pain in non intubated critically ill patients unable to self report: An adaptation of the behavioral pain scale. Intensive Care Medicine, 35, 2060-2067.

Puntillo, K., Morris, AB., Thompson, CL., Stanik-Hutt, J., White, C., \& Wild LR. (2004). Pain behaviors observed during six common procedures: Results from thunder project II. American Journal of Critical Care, 32(2), 421-7.

Polit, D. F., \& Beck, C. T. (2012). Nursing research: Generating and assesing evidence for nursing practice. ( $9^{\text {th }}$ ed.). Lippincott Williams and Wilkins.

RSUD M. Yunus Bengkulu. (2016). Data: View record. Diunduh dari http://sirs.yankes.kemkes.go.id/rsonline/ data_view.php? editid1 $=323$.

Rahu, M., \& Grap, M. (2010). Facial expression and pain in the critically ill noncommunicative patient: State of science review. Intensive Critical Care Nursing, 26, 343-52.

Sriwahyuningsih, I. (2016). Studi literatur: Instrumen pengkajian nyeri pada pasien kritis dewasa yang terpasang ventilator. Jurnal Keperawatan dan Pemikiran Ilmiah, 2(2), 1-7. 
Stites M. (2013). Observational pain scales in critically ill adults. American Association of Critical-care Nurses, 33(3), 68-79.

Sudjana, N. (2013). Dasar-dasar proses belajar. Bandung: Sinar Baru Algesindo.

Sutari, M., Abdalrahim, MS., Hamdanmansour, AM., \& Ayasrah, SM. (2014). Pain among mechanically ventilated patients in critical care units. Journal of Research in Medical Science, 19(8), 72632. 


\section{HALAMAN INI SENGAJA DIKOSONGKAN}

